\title{
DIE NIEU-TESTAMENTIESE GETUIENIS AANGAANDE DIE NEDERDALING VAN CHRISTUS NA DIE HEL
}

1. Ter Inleiding.

Die bedoeling van hierdie opskrif, soos dit voorkom op die program van die predikantevergadering ${ }^{1}$ is seker nie, dat vooraf aanvaar word dat

25) Inst. II, xvi, 8 .

1) Hierdie lesing is voorgedra op die Predikante-vergadering van die Ned. Hervormde Kerk te Pretoria op 5 Sept. 1961. 
Christus na die hel neergedaal het, en dat ons dan net moet toelig wat die Nuwe Testament daaromtrent sê nie. Die vraag is: hoe moet die artikel in ons geloofsbelydenis geformuleer word? En is daar gegewens in die Nuwe Testament wat ons hierin kan help? Moet ons sê: Christus het neergedaal na die hel, soos dit tans in ons kerkboek staan, en soos ons op Sondae in die erediens bely? Of sal dit juister wees om te spreek van die doderyk? Wat is die bedoeling van hierdie woorde in die Apostolicum?

Waar moet ons hier gebegin? Die Apostolicum het uit die trinitariese doopbelydenis gegroei. Die woorde: descendit ad inferna is een van die laaste toevoegings wat gemaak is ${ }^{2}$. Dit is afkomstig uit die Westerse latynsprekende gedeelte van die Christelike kerk. Ons weet nie presies wanneer hierdie woorde ingevoeg is nie. Ons weet ook nie met sekerheid watter bybeluitsprake as skrifgronde gebruik is vir hierdie toevoeging nie. Agterna is wel op allerlei bybeluitsprake 'n beroep gedoen om te dien as bewysplase vir hierdie belydenis van die neerdaling van Christus.

Dit is wel duidelik dat die enigste regte beginpunt vir die ontrafeling van die probleem is, dat ons begin met die latynse bewoording van die artikel self. Dit is: descendit ad inferna. Die Credo van Athanasius het: descendit ad inferos. Kom hierdie uitdrukkinge in die Latynse Bybel voor? Kan mens uit die Latynse Bybel vasstel watter bybeluitsprake moontlik ten grondslag kan lê aan hierdie woorde: descendit ad inferna (of inferos)? Prof. Gemser het in H.T.S., I. 116v 'n hele aantal tekste in die $\mathrm{Ou}$ Testament opgenoem waarin beide uitdrukkinge: descendit ad inferna, en: descendit ad inferos voorkom. En op al hierdie plekke, so het Prof. Gemser aangetoon, is infernus of inferi die vertaling van die hebreeuse woord sheōl.

\section{Die Sheōl-voorstelling in die $\mathrm{O} u$ Testament.}

Die sheol is in die Ou Testament die onderaardse doderyk wat sonder onderskeid alle mense, goed of sleg, na hulle dood, vir altyd ontvang. As 'n land van diepe donkerheid en stilte hou dit vir altyd almal vas wat agter sy poort ingegaan het. As wesenlose skaduwees moet sy bewoners in die land van vergetelheid ' $n$ vreugdelose bestaan voer. Die somberste van hierdie bestaan is, dat mens afgesny is van die gemeenskap en die diens van God. Die woorde: infernus, inferi, hebr. Sheōl kan die beste vertaal word as: onderwêreld, doderyk.

\section{Hades-voorstellinge in die Nuwe Testament.}

Die brug na die Nuwe Testament kry ons via die Septuagint wat Sheōl deurgaans vertaal het met hadés. So het via die Septuagint hadés die gebruiklike woord geword vir die doderyk, die infernus of inferi,

2) Vgl. Hervormde Teologiese Studies, Jaargang I, 1944, bl. 32, 34, 116. 
—n dit wel in die hellenistiese Jodendom, in verskeie Pseudepigrawe, en ook in die Nuwe Testament.

Die woord „hadés" kom in die Nuwe Testament in elf tekste voor: Matt. 11:23; 16:18; Luk 10:15; 16:23; Hand 2:27, 31; 1 Kor 15:55? Openb. $1: 18 ; 6: 8 ; 20: 13,14$. Dit is nodig dat ons hierdie hadés-uitsprake kortliks beskou.

In Matt 11:23-Luk 10:15 lees ons die woorde van Jesus: En jy, Kapernaum wat tot die hemel toe verhoog is, jy sal tot die doderyk toe neergestoot word (heōs hadou katabésé of katabibasthésé). In hierdie uitspraak lê die voorstelling dat die hades diep daar onder lê, diep onder die aarde, sodat mens daarheen moet afklim, of daarheen afgegooi kan word. Hier spreek ook die gedagte mee dat mens in die hadés die gemeenskap van God moet mis. Kapernaum wat so hoog bevoorreg was deur die teenwoordigheid, die werk en prediking van Christus, sal van hierdie godsgemeenskap wat hulle nie waardeer het nie, neergestoot word tot in die hadés, buite die gemeenskap van God.

In Matt. 16:18 het ons die woorde van Jesus: En Ek sê ook vir jou: Jy is Petrus, en op hierdie rots sal Ek my gemeente bou, en die poorte van die doderyk (pulai hadou) sal dit nie oorweldig nie. Die uitdrukking pulai hadou is afkomstig van Jes. 38:10: Shearé sheöl, wat deur die Septuagint vertaal is as pulai hadou. Hieragter staan nog die ou-testamentiese sheōl-voorstelling waarvolgens die doderyk voorgestel word as 'n vesting met poorte, - om vir ewig vas te hou die wat daar ingaan. Die gemeente van Christus sal nie agter daardie poorte kom nie, omdat Jesus die sleutels van die koninkryk van die hemele aan die kerk gegee het, sodat hulle kan ingaan tot die lewe.

Die voorstelling van die hadés met poorte en slotte vind ons ook in Openb. 1:18. Hier spreek Christus wat die sewesterre in sy regterhand hou $^{3}$, wat dus die Albeheerser, die Triumfator is: en Ek was dood en kyk, Ek leef tot in alle ewigheid. Amen. En Ek het die sleutels van die dood en die doderyk (kai echō tas kleis tou thanatou kai tou hadou). Christus was dood en in die doderyk, maar nou het $\mathrm{Hy}$ die sleutels van die dood en doderyk! Nou leef $\mathrm{Hy}$ tot in alle ewigheid. As Christus dood was en gevolglik ook in die doderyk was, agter daardie poorte van waar niemand terugkeer nie, maar nou die sleutels van die dood en die doderyk het, dan lê daarin duidelik die voorstelling dat Christus teruggekeer het as die Oorwinnaar van die dood en die doderyk, en voortaan mag en beskikking daaroor het.

Die woorde „dood” en „doderyk" kom baie dikwels saam voor in die Ou Testament, en wel as parallelismes,-miskien sinonieme parallelismes, miskien as aanvullende parallelismes. En dit wil sê dat dood en doderyk saamhoort. Wie sterwe gaan as vanself na die doderyk. Die

2) Vgl. Openb. 1:16. 
dooies word begrawe. Maar die graf is die bek van die doderyk, waardeur die oorledenes afdaal na die doderyk. So is dan ook die samestelling van graf en doderyk te verstaan, bv. in Ps 16:10. Vir die Christelike gemeente van die eerste eeu was dit dus ' $n$ vanselfsprekende voorstelling uit die $\mathrm{Ou}$ Testament, dat as Christus gely en gesterwe het, en begrawe is, hy dan ook neergedaal het na die doderyk. Die graf is die bek van die doderyk wat toegang tot die doderyk verleen. So gesien word die woorde: ,,gesterwe en begrawe" nogeens onderstreep deur die woorde: neergedaal na die doderyk. Die neerdaal na die doderyk is die volle konsekwensie van die woorde: gesterwe en begrawe. Hiermee wil die belydenis sê dat Jesus Christus konsekwent die weg van alle mense gegaan het tot die uiterste toe, nl. om te sterwe en neer te daal na die doderyk. Dit is die volle konsekwensie van sy menswording.

So kom dan ook dood en doderyk saam voor in Openb $1: 18 ; 6: 8$; $20: 13,14$. In Openb $6: 8 ; 20: 13,14$ word ho thanatos kai ho hadés gepersonifiëerd voorgestel: die een wat op die vaal perd sit is die dood, en die doderyk het hom gevolg. Saam trek hulle uit om 'n vierde deel van die aardbewoners dood te maak, Openb. 6:8. In Openb. 20:13, 14 lees ons: „En die dood en die doderyk het die dode gegee wat daarin was ... en die dood en die doderyk is in die poel van vuur gewerp. Dit is die tweede dood."

Dieselfde motief van die oorwinning van Christus oor die dood en die doderyk as wat ons in Openb. 1:18 gevind het, is ook aanwesig in $1 \mathrm{Kor} 15: 54,55$ : Die dood is verslind in die oorwinning. Dood waar is jou angel? Doderyk waar is jou oorwinning? Die oorwinning is behaal oor die dood en die doderyk. Die oorwinning is behaal deur Jesus Christus, deur sy opstanding uit die dode (ek tön nekrön) 1 Kor 15:12, 20. Hy is opgewek ek tōn nekrōn; Hy het die eersteling geword van die wat ontslaap het. Hy is opgewek van tussen die dode uit, tot wie Hy behoort het. Van almal wat in die slaap van die doderyk versink het, is Christus die eerste een wat wakker geword het. Hy is die eersteling van die ontslapenes, 1 Kor 15:20. Die eersteling (aparché) het hier die betekenis van die eerstelingoffer: Christus is as eerstelinggerf deur die opstanding geoes tot die lewe, en daatom is Hy die waarborg van die opstanding van al die ontslape gelowiges. Hy is die Eersgeborene uit die dode (prōtōtokos ek tōn nekrōn), Koll 1:18; Openb. 1:5. In al hierdie uitsprake is dit duidelik dat Christus tot die dode in die doderyk behoort het, en dat $\mathrm{Hy}$ deur sy opstanding tussen die dode uit opgestaan het, deur God opgewek is. Die voorstelling van die doderyk en van Christus in die doderyk word dus weerspieël in die verskillende sinswendinge waarmee die opstanding van Christus beskryf word.

In Hand. 2:27, 31 sien Petrus in die Septuagintlesing van Ps. 16:10 'n profesie van die opstanding van Christus, nl. ,,dat sy siel nie in die doderyk verlaat is, of ook sy vlees verderwing gesien het nie." Petrus wil hier 
sê dat die siel van Christus in die doderyk was, maar nie daar verlaat is nie, omdat God Hom uit die dode opgewek het. Ook Hebr. 13:20 weet dat God ons Here Jesus uit die dode teruggebring het, (ho anagagōn ek nekrōn ton kurion émōn jesoun).

Die voorstelling van Christus in die doderyk vind ons ook in Matt. 12:40: Soos Jona drie dae en drie nagte in die buik van die groot vis was, so sal die Seun van die mens drie dae en drie nagte in die hart van die aarde wees (en té kardia tés gés.) Hierdie uitdrukking: in die hart van die aarde, beteken seker iets meer as net die graf. Volgens Jona 2:2 was die gebed van Jona uit die ingewande van die vis: „uit die binneste van die doderyk het ek geroep om hulp." Ons mag aanneem dat Matt. 12:40 hieraan denk, en dat :,,in die hart van die aarde" dieselfde betekenis het as ,in die binneste van die doderyk"; dit is die Ou-Testamentiese voorstelling dat die Sheōl, die doderyk, diep onder die aarde lê. Maar dis ook die gangbare voorstelling in die Nuwe Testament. Teenoor die hemel as die hoogste hoogte is die hadés die diepste diepte, in die hart van die aarde.

In Ef. 4:9 skryf Paulus: Maar dit: Hy het opgevaar-wat beteken dit anders as dat Hy eers neergedaal het in die onderste dele van die aarde. In Ef. 4:1-16 spreek Paulus oor die eenheid van die Christelike kerk, en oor die veelheid van gawes wat Christus in die gemeente gee. Dan haal hy uit die geheue Ps. 68:19 vry aan in Ef. 4:8: Toe Hy opgevaar het in die hoogte het $\mathrm{Hy}$ die gevangenes gevange geneem en gawes aan die mense gegee. Volgens Paulus is Hy wat opgevaar het, Christus. Dat Hy opgevaar het, veronderstel dat $\mathrm{Hy}$ tevore eers neergedaal het. Paulus sien hierdie opvaar en neerdaal nou in volstrekte sin, as hy sê dat Christus wat neergedaal het in die onderste dele van die aarde (eis ta katōtera meré tés gés) dieselfde is as $\mathrm{Hy}$ wat opgevaar het bokant al die hemele. Hierdie uitdrukking: neergedaal in die onderste dele van die aarde-sluit aan by die Ou-Testamentiese Sheōl-voorstelling, en beteken meer as sy menswording, ook méér as graf of dood. Soos „,die hart van die aarde" van Matt. 12:40 beteken dit: die diepte van die doderyk,--as teenstelling tot: bokant al die hemele,-sodat ons ook hier die voorstelling aanwesig vind van die neerdaal van Christus na die doderyk.

In Rom. 10:6, 7 waarsku Paulus,--met 'n vrye aanhaling van Deut. 30:11-14 teen 'n onmoontlike voorneme as hy sê: Moenie in jou hart sê: Wie sal in die hemel opvaar, naamlik om Christus af te bring, of: Wie sal in die afgrond (abussos) afdaal, naamlik om Christus uit die dode op te bring? In hierdie hoofstuk stel Paulus die geregtigheid wat uit die geloof is teenoor die geregtigheid uit die wet. In Rom. 10:7 is die woorde: opvaar in die hemel, en: afklim in die doderyk (abussos)-beeldsprakige beskrywinge vir dit wat vir die mens onmoontlik is. Abussos het hier die betekenis van: doderyk. Paulus parafraseer hierdie vermaning dan in Christologiese sin: Jy kan nie die Christus uit die hemel afbring of uit die doderyk opbring nie,--want Hy het al gekom, en is naby ons deur sy 
Woord. Die geregtigheid van die geloof hoef dit nie te doen nie, maar moet dit aanvaar as die volbragte werk van God. Hierdie woorde en gedagtegang van Paulus sou betekenloos gewees het, as hulle nie 'n tradisie kon veronderstel dat Christus wel in die hadés was, en weer vandaar opgekom het nie.

\section{1 Petr. 3:18-20 en 2 Petr. $4: 6$.}

Een van die merkwaardigste uitsprake van die Nuwe Testament waarop baie dogmatici hulle beroep om te dien as bewysplaas vir die neerdaling van Chrisuts na die hel (doderyk) is 1 Petr. 3:18-20. ${ }^{4}$ Hier word gespreek van Christus wat wel gedood is na die vlees, maar lewend gemaak van die Gees, in wie Hy ook heengegaan en gespreek het (ekéruksen) vir die geeste in die gevangenis, wat eertyds ongehoorsaam was toe die lankmoedigheid van God een maal gewag het in die dae van Noag . . . Soms word 1 Petr. 4:6 hiermee in verband gebring: Want daarom is ook aan die dode die evangelie verkondig, sodat hulle wel geoordeel kan word na die mens in die vlees, maar lewe na God in die gees.

In 1 Petr. 3:19 het ons in die woorde: die geeste in die gevangenis, wat eertyds ongehoorsaam was ... - waarskynlik'n weerspieëling van die hadesvoorstelling afkomstig uit die Joodse apokaliptiek, waarvolgens die doderyk verskillende afdelinge bevat, en ook dien as tydelike verblyf van die ongehoorsames tot die laaste oordeel. ${ }^{5}$ Die afdeling vir die ongehoorsames of goddeloses word meermale 'n gevangenis genoem. Volgens 1 Petr. 3:19 word die geeste van die ongehoorsames uit die dae van Noag dan in die gevangenis bewaar, in afwagting van die laaste oordeel. In 1 Petr. 3:9 kan ons dan die voorstelling hê dat toe Christus in die doderyk was, Hy ook heengegaan het na die afdeling waar die geeste van die ongehoorsames uit die dae van Noag bewaar word, om ook aan hulle wat hier genoem word as voorbeeld van die mees vol-hardende ongehoorsaamheid teen God,-om ook aan hulle sy oorwinning te proklameer. Dit kan ook wees dat die ,heengaan" van Christus (poreutheis) van 3:19 in 1 Petr. $3: 22$ weer opgeneem word, en daar verder verklaar word as 'n poreutheis eis ton outanon, 'n heengaan na die hemel, terwyl engele en kragte en magte aan Hom onderwerp is. As die heengaan van Christus in 3:19 soos in 3:22 ook sien op die hemelvaart, dan het ons in 3:19 en 3:22 parallele uitsprake oor die oorwinning van Christus, wat wil sê: Deur die triomfantelike heengaan van Christus na die hemel is sy oorwinning geproklameer tot in die dieptes van die doderyk, tot in daardie dieptes waar ongehoorsame geeste in bewaring gehou word vir die laaste oordeel. Parallel hiermee staan dan in 1 Petr. 3:22 die uitspraak dat Christus as Oorwinnaar heengegaan het na die hemel, terwyl engele en magte en kragte aan

4) Vgl. Kittel, Theol. Wörterbuch zum N.T. III, 706.

s) Vgl. Henog 22, waar die verskillende afdelings, volgens apokaliptiese voorstelling, beskryf word. 
Hom onderwerp is. In 1 Petr. 3:19 word nie uitdruklik gesê dat Christus heengegaan het na die geeste in die gevangenis nie. In die werkwoord ekéruksen lê ook nie noodwendig die verkondiging van die heil nie. ${ }^{6}$ In die verse 3:18-22 word vir die Christene wat onskuldig by die lyding van Christus as voorbeeld voorgehou, maar die nadruk gelê op die oorwinning van Christus. Christus is gedood na die vlees, d.i. na sy menslike sterflike natuur. Die volgende woorde: zōopoiétheis de pneumati vertaal die Afrikaanse Bybel: maar lewend gemaak deur die Gees (hoofletter.) Dit is egter beter om te vertaal: lewend gemaak na die gees (klein letter), en gees beteken dan: die geestelike bestaan, die geestelike natuur van Christus, sodat hier net soos in 4:6 ,na die vlees" staan teenoor ,na die gees", en lg. sien dan op die pneumatiese wese van Christus. „Gedood na die vlees, en lewend gemaak na die gees" beteken dan: Christus het die vleeslike sterflike lewe afgelê en 'n geestelike opstandingslewe verkry. Die woorde ,en hō . . p poreutheis" vertaal die Afrikaanse Bybel: ,in Wie" (hoofletter) Hy heengegaan het", bedoelende die Heilige Gees. Christus sou dan in die Heilige Gees heengegaan het en gepreek het vir die geeste in die gevangenis. Ons vertaal ,en hö-" liewer met: waarin, want hier word nie die Heilige Gees bedoel nie, maar die staat van die geestelike opstandingslewe van Christus waarin „Hy heengegaan het en gepreek het vir die geeste in die gevangenis. Die heengaan van Christus geskied dus in die staat van sy geestelike opstandingslewe, dus ná sy opstanding, en val dus nie meer onder sy lyding en vernedering nie, maar is reeds deel van sy verhoging. Deur sy triomfantelike heengaan na die hemel het Hy sy oorwinning geproklameer tot in die dieptes van die doderyk. Parallel hiermee staan dan in 1 Petr. 3:22; Christus het heengegaan na die hemel, terwyl engele en magte en kragte aan Hom onderwerp is. As hierdie verklaring vir ons aanneemlik sou wees, kan 1 Petr. 3:19 nie diens as bewysplaas vir

die nederdaling van Christus na die doderyk nie. In die woorde: preek vir die geeste in die gevangenis vind sommiges die Rooms-Katolieke opvatting van 'n werklike neerdaling van Christus na die hel. Die ou gereformeerde verklaring wat reeds by Augustinus te vind is, sê dat hier bedoel word dat die Gees van Christus wat volgens 1 Petr. $1: 10 \mathrm{v}$. reeds in die profete was, deur middel van Noag gepreek het vir sy verharde tydgenote.

Soms word 1 Petr. 4:6 in verband gebring met die voorgenoemde 1 Petr. 3:19. In 1 Petr. 4:6 lees ons: ,Want daartoe is ook aan die dode die evangelie verkondig (tois nekrois euéngelisthé) sodat hulle wel geoordeel kan word na die mens in die vlees, maar lewe na God in die gees." Staan hierdie woorde moontlik in verband met 1 Petr. 3:19? Is daar 'n verband tussen ,,die verkondiging van die evangelie aan die dode” en: „die preek vir die geeste in die gevangenes"? 'n Verband tussen hierdie twee tekste

B) Vgl. Theol. Wörterbuch Z.N.T. waarin Friedrich as die mees kenmerkende betekenisse van kerussein aangee: proklameer, aankondig, die uitroep van 'n gebeurtenis. 
is nie noodsaaklik nie. Die verklaring van 4:6 lewer baie probleme op. Van die groot aantal verklaringe noem ons hier net drie: ${ }^{7}$

1. Die dode aan wie die evangelie verkondig is, is alle dooies van die begin af, (in aansluiting by die voorafgaande 4:5 waar gesê word dat God gereed staan om lewende en dode, d.i. alle mense te oordeel). Volgens hierdie opvatting sou Christus dan nie net gepreek het aan die geeste in die gevangenis nie, (1 Petr. 3:19), maar het $\mathrm{Hy}$ ook aan al die dode in die doderyk die evangelie gaan verkondig en aan hulle 'n uitsig op die heil geopen. Dit sou egter onverstandig wees om enkel op grond van hierdie bepaalde verklaring van 4:6 so'n belangrike leerstelling te bou nl. dat aan die dode die evangelie nog verkondig sou word, d.i. dat ná hulle sterwe die uitsig tot die heil vir die ongehoorsames nog oopstaan.

2. 'n Tweede verklaring wat ons hier noem is dat die dode in $4: 6$ die gelowiges van die vorige generasie was, wat die evangelie nog tydens hulle lewe gehoor het, maar intussen reeds oorlede is. Hier het Petrus, dan te doen met ' $n$ situasie soortgelyk aan die wat bespreek is in 1 Thess. 4:13-18, waar persone in die gemeente in Thessalonika verontrus is oor die uiteindelike lot van dié wat ontslaap het voor die wederkoms van Christus. Die dode is in 4:6 die ontslape gelowiges.

3. Die derde, en volgens samehang geoordeel, waarskynlikste verklaring, (maar wat die tweede genoemde verklaring nie hoef uit te sluit nie) is dat ,die dode" van 4:6 die eerste martelare van die Christelike kerk is. Hulle is geoordeel ,,in die vlees" (sarki) toe die vonnis van die marteldood oor hulle uitgespreek is. Hulle is geoordeel ,na die mens" (kata anthrōpous, d.w.s. in die oog van mense, soos mense dit beskou, het hulle lewe geëindig in die docd. Die apostel handel hier oor die moeilike lot van vervolging en lyding en dreigende martelaarskap vir die Christene in KleinAsië. Hy wil hulle troos en bemoedig om vas te staan, ook al bring dit die dood mee. W'ant al sou dit vir hulle aardse lewe, na die mens geoordeel, die dood en ondergang beteken, tog sal hulle deur God opgewek word tot die ewige lewe. Hierdie voorlopige veroordeling tot die martelaarskap onder die hand van mense word deur God self reggestel. Ons kan hierdie vers dan ongeveer só parafraseer: Want met hierdie doel is ook aan die dode (die martelaars) die evangelie verkondig, sodat hulle, soos mense dit beskou, wel geoordeel is na die vlees, maar na die oordeel van God sou lewe na die gees, dit is: ewig in die ryk van die gees, nie meer sterflik en verganklik nie, maar verheerlik in die ewige lewe.

As hierdie of 'n verwante verklaring vir ons anneemlik is, kan $4: 6$ nie dien as bewysplaas vir die neerdaling van Christus na die doderyk nie.

7) Vgl. vir die verklaring van 1 Petr. 4:6 Theol. Wörterbuch Z.N.T., IV 897 ff., by nekros. Sien ook vir meer besonderhede, skrywer se verklaring van I Petr. 3:19 en 4:6 in Die Bybel met verklarende Aantekeninge. 
By die gehenna-uitsprake in die Nuwe Testament hoef ons nie lank stil te staan nie. In die Nuwe Testament word hadés weergegee met: infermus of inferi, en gehenna met gehenna. Die gehenna-voorstelling duik in die 2de eeu v.C. op in die apokaliptiese literatuur van die Palestynse Jodendom. Die Joodse apokaliptiek het die berugte dal van Hinnom, suid van Jerusalem, gemaak tot die plek van die eindgerig. Dáár sal die vuurhel oopbreek. Oorspronklik was dit die eskatologiese strafplek na die laaste oordeel, maar slegs vir die afvallige Israeliete, (vgl. Dan. 12:2); spoedig egter het dit in die apokaliptiek geword die versamelplek van alle goddeloses, en teen die end van die eerste eeu n.C. ken die rabbynse geleerdes die gehenna as tydelike en ewige strafplek, sodat die hadés as tussentydse strafplek vir die goddeloses deur die gehenna verdring is.

Die hadés-voorstellinge het in die tyd tussen O.T. en N.T. 'n hele ontwikkeling deurgemaak, en hierdie ontwikkeling is ook beïnvloed deur die opkoms van die gehenna-voorstelling. Die gevolg is dat ons soms in die Nuwe Testament verskillende voorstellinge uit die verskillende stadia naas mekaar vind.

Ons skets kortliks hierdie ontwikkeling. Deur die opkoms van die opstandingsgeloof (vgl. Jes. 26:19 as een van die oudste uitsprake) is die Ou-Testamentiese voorstelling van die Sheōl as ewige verblyf vir almal verander tot slegs 'n tydelike verblyf van die vromes tot aan die opstanding. Vir die vromes het so die Sheōl 'n tydelike verblyf geword tussen hulle docd en opstanding. Deur die opkoms van die vergeldingsgedagte is verder die lot van die regverdige en goddelose siele as verskillend voorgestel, en hulle verblyfplek in die Sheōl, of die hadés ruimtelik geskei, sodat daar in hadés verskillende afdelinge is. ${ }^{8}$ Vir die vromes was die hadés, die doderyk toe 'n plek waar hulle tydelik rus tot die dag van die opstanding maar vir die goddeloses 'n plek van voorlopige straf tot die opstanding, vgl. Luk. 16:23. Die ryk man in die gelykenis het gesterwe en is begrawe en het gevolglik in die doderyk gekom. En toe hy in die hadés sy oë ophef, terwyl hy in die smarte was ... (hup-archōn en basanois). Dit het ook meegebring dat die hadés verskillende afdelinge het, vgl. Hen. 22. Die ryk man in die gelykenis, Luk. 16 sien Abraham van ver af en Lasarus dan sy hoesem, maar daar is 'n diep kloof wat hulle skei. In 1 Petr. 3:19 word gespreek van die gevangenis van die geeste wat ongehoorsaam was in die dae van Noag. 'n Variasie van hierdie voorstelling vind ons ook in 2 Petr. 2:4 en Jud. 6 waar gespreek word van die tydelike strafplek van die ongehoorsame engele, wat in die Tartarus gewerp is, (tartarösas) om daar vir die oordeel in bewaring gehou te word. Dieselfde voorstelling vind ons in die afgrond (abussos) wat toegesluit kan word, en wat dien as gevangenis van die ongehoorsame geeste, die demone, en ook vir die

*) Vgl. Hen. 22. 
draak, die bees vir duisend jaar.' 'n Verdere ontwikkeling wat via die hellenistiese Jodendom in Palestina ingekom het was die voorstelling dat die siele van die vromes in die sterwensuur onmiddellik na die hemelse saligheid, die paradys gegaan het, en die siele van die goddeloses na die pyn van hades, vgl. Luk. 16:19-31. Die voorstelling dat die siele van die vromes onmiddellik ná hulle sterwe na die hemelse saligheid, na die paradys gaan, is goed verteenwoordig in die Nuwe Testament. Ons noem enkele voorbeelde: Luk 23:43: ,vandag met My in die paradys"; Luk 16:9: , as julle die lewe verlaat . . . hulle julle in die ewige tente kan ontvang"; Filip. 1:23: ,,verlange om heen te gaan en met Christus te wees"; 2 Kor. $5: 8:, \ldots$ uit die liggaam uit te woon, en by die Here in te woon." Die gevolg van hierdie voorstelling was dat die hadés elke betrekking met die vromes verloor het, en dit uitsluitlik geword het 'n strafplek vir die goddeloses. Dit het daartoe meegewerk dat by die rabbyne die gehennavoorstelling die hadés verdring het, en die plek van tydelike en ewige straf geword het, sodat die hadés nog net as verswakte sinoniem gebruik is, of uitgelê is as ,graf" ,hiernamaals".10

Tydens die ontstaan van die Nuwe Testament egter, was hierdie ontwikkelingsproses, nog aan die gang. Dit word weerspieël deur die feit dat ons meermale voorstellinge uit die verskillende stadia na aan mekaar in die Nuwe Testament vind. Neem as voorbeeld: Luk. 23:43 en 46 teenoor die voorstelling wat ons vind in Mat. 12:40 en Hand 2:27, 31 .

Die nuwe Testament weerspieël die gehenna slegs as ewige, finale strafplek van die goddeloses, ná die laaste oordeel, as vuurhel, die gehenna van vuur. Prinsipieel vir die verstaan van die gehenna-uitsprake in die Nuwe Testament is dat die Nuwe Testament self skerp onderskei tussen die hadés en die gehenna, en wel as volg: Die hadés ontvang die goddeloses slegs in die tyd tussen dood en opstanding. Die hadés is tydelik, en word aan die end saam met die dood in die hel gewerp, in die poel van vuur, Openb. 20:14, terwyl die gehenna die ewige strafplek is, ná die laaste oordeel. In die hadés ondergaan die goddeloses dus slegs 'n voorlopige straf, terwyl hulle in die gehenna die ewige pyn verduur. Die smarte van die veroordeeldes in die gehenna word met verskillende sinswendinge beskryf as: vervalle wees aan die helse vuur, Matt. 5:22; met die hele liggaam in die hel gewerp word, Matt. 5:29, 30; siel en liggaam verderwe in die hel, Matt. 10:28; Luk. 12:5, in die ewige vuur gewerp te word Matt. 18:8; kind van die hel te wees, Matt. 23:15; die oordeel van die hel wat nie ontvlug kan word nie, Matt. 23:33; in die hel te gaan, in die onuitbluslike vuur, Mark. 9:43. Almal wat nie opgeskryf is in die boek van die lewe nie, word gewerp in die poel van vuur, (eis tén limnén tou puros), Openb. 20:15. Die gehenna word in Matt. 25:41 genoem: die ewige vuur wat berei is vir

D) Vgl. Luk. 8:31; Openb. 9:1, 2;9:11; $11: 7 ; 20: 1,3$.

10) Vir die ontwikkeling van hierdie voorstellinge sien Strack-Billerbeck, Kommentar zum Neuen Testament, IV 1016ff, in sy Ekskurs oor Sheol, Gehinnom en Gan Eden, asook Kittel, Thwb. I, $655 \mathrm{ff}$ oor gehenna. 
die duiwel en sy engele; in Matt. 13:42, 50 die vuuroond waar geween en gekners van die tande sal wees. Die dier, die Satan en sy vals profeet word gegooi in die vuurpoel wat met swawel brand, Openb. 19:20; tenslotte word ook die dood en die doderyk in die poel van vuur gegooi, Openb. $20: 14$.

Terwille van hulle wat graag vas wil hou aan die bewoording in ons kerkboek: neergedaal na die hel, het ons met nadruk al die gehennauitsprake in die Nuwe Testament opgenoem, sodat dit duidelik kan wees, dat die Nuwe Testament die gehenna slegs ken as die eskatologiese strafplek, ná die laaste oordeel, as die vuurhel, die poel van vuur, die ewige vuur,_-sodat alleen daarom reeds die voorstelling dat Christus tussen sy dood en opstanding na die gehenna sou neergedaal het, uitgesluit is. Nêrens spreek die Nuwe Testament van die neerdaling van Christus na die gehenna, die hel nie.

\section{Samevatting:}

1. Vir die voorstellinge van die doderyk mak die Nuwe Testament tot 'n groot mate gebruik van die Ou-Testementiese sheōl-voorstellinge, maar die Nuwe Testament weerspieël natuurlik ook die veranderde en veranderende voorstellinge van die Joodse apokaliptiek, bv. van die hadés en die gehenna. Daarom is die voorstellinge in die Nuwe Testament ook nie altyd eenvormig nie, en weerspieël dit soms verskillende hadésvoorstellinge naas mekaar. Vir 'n juiste eksegese moet hierdie ontwikkelingsproses in rekening gebring word.

2. Die woorde van die Apostolicum: „,neergedaal na die doderyk" word na sy waarskynlikste oorsprong en betekenis, en na sy plek en volgorde tussen die ander woorde in, die beste verklaar deur uitsprake soos Hand. 2:27, 31: (dat sy siel nie in die doderyk verlaat is nie); Matt. 12:40: (drie dae en drie nagte in die hart van die aarde); Ef. 4:9; (neergedaal in die hart van die aarde); Dit sien op die staat van die dood waarin Christus as Middelaar verkeer het tussen sy sterwe en sy opstanding. Die voorstelling van Christus in die doderyk, en dit in sy staat van vernedering, is ook vervat in die herhaalde parallelismes: dood en doderyk; verder in die uitdrukking dat Christus opgestaan het ek tōn nekrōn, tussen die dodes uit, tot wie $\mathrm{Hy}$ behoort het, 1 Kor. 15:12, 20. Hy het in die doodslaap gelê tussen die dooies as één van hulle.

3. Maar daar is ook Nieu-Testamentiese uitsprake wat die voorstelling bevat dat die neerdaling van Christus na die doderyk deel is van sy verhoging en uitloop op sy oorwinning, vgl. Openb. 1:18: Hy wat dood was, en in die doderyk, lewe in ewigheid, en Hy het nou die sleutels van die dood en van die doderyk. Deur sy dood het Christus hom tot niet kom mak wat mag oor die dood het, dit is die duiwel, Hebr. 2:14. Hieragter lê die voorstelling dat Christus in sy worsteling met dood en hadés die sleutels bemagtig het en uit die dood en hadés teruggekeer 
net na die lewe, vgl. 1 Kor. 15:54v. Die oorwinningsmotief lê ook in 1 Kor. 15:20: Christus het die eersteling geword van die ontslapenes. Hy het opgestaan van tussen die dode uit, ek tōn nekrōn. Hy is prötotokos ek tōn nekrōn, Kol. 1:18; Openb. 1:5.

4. Die motief van vernedering en verhoging, neerlaag en oorwinning, as 'n twee-eenheid vind ons in uitsprake soos Ef. 4:10: (Hy wat neergedaal het is dieselfde as Hy wat opgevaar het bokant al die hemele,); Openh. 1:18: Hy wat dood was, lewe nou. Hy wat in die dood en in die Hades was, het nou die sleutels van die dood en die hadés. Volgens Kol 2:14, 15 het Christus aan die kruis oor sy vyande getriomfeer. Hy het opgestaan ek tōn nekrōn. Die dieptepunt van sy vernedering is tegelyk die keerpunt, die beginpunt van sy verhoging.

5. Volgens die mees waarskynlike verklaring kan 1 Petr. 3:19 en 4:6 nie dien as bewysplase vir die nederdaling van Christus na die doderyk nie.

6. Die woorde van die Apostolicum: descendit ad inferna (inferos) staan in geen verband met die gehenna-voorstelling wat ons in die Nuwe Testament vind nie. Die Nuwe Testament ken die gehenna slegs as die finale eskatologiese strafplek, die vuurhel wat sal verskyn by die laaste oordeel. Alleen hierom reeds is die voorstelling uitgesluit dat Christus tussen sy dood en opstanding na die gehenna sou neergedaal het. Nêrens spreek die Nuwe Testament van 'n neerdaling van Christus na die gehenna, die hel nie.

Pretoria,

September, 1961.

S. P. J. J.. van Rensburg. 